\title{
Proposta de gestão de resíduos sólidos do município de Rodolfo Fernandes/RN
}

O aumento da geração de Resíduos sólidos, ocasionado pelo grande crescimento populacional no mundo, é um dos maiores problemas enfrentados na atualidade. O Brasil tornou-se o 3 o maior produtor de resíduos sólidos da América Latina, atrelado a uma má eficiência da gestão e atingindo também a todas as regiões do país, isso se tornou um dos maiores entraves da gestão pública, atualmente. Diante disto, este trabalho teve o objetivo de elaborar uma proposta de gestão de resíduos sólidos para o município de Rodolfo Fernandes/RN, contemplando desde as etapas de diagnostico às propostas de ações. Foi realizado um estudo exploratório, baseando-se em pesquisas em órgãos oficiais e em documentos técnicos e visitas e levantamento de dados in loco. Foi diagnosticado um gerenciamento ainda deficitário dos resíduos sólidos municipais, dispostos em vazadouro a céu aberto, com uma estimativa de geração diária per capita abaixo das médias nacionais e regionais. A composição gravimétrica demonstrou uma maior porcentagem de resíduos orgânicos apesar dos valores estarem consideravelmente capita abaixo das médias nacionais e regionais. A composição gravimétrica demonstrou uma maior porcentagem de resíduos orgânicos apesar dos valores estarem consideravelmente implantação de coleta seletiva. O prognostico apresentou um cenário da necessidade de imediata adoção de mudança na disposição final dos resíduos e de implementação de associação de catadores que possibilitem uma coleta diferenciada, apresentando também ações estratégicas e medidas executivas de gerenciamento dos resíduos sólidos do município, além de práticas que possibilitem a disseminação da responsabilidade compartilhadas entre os atores sociais envolvidos. Por fim, salientou-se a carência de planejamento e estratégias de gerenciamento e gestão dos RSU, tanto na fase operacional, quanto na percepção financeira.

Palavras-chave: Coleta Seletiva; Composição Gravimétrica; Gerenciamento de Resíduos Sólidos, Catadores de Materiais Recicláveis.

\section{Solid waste management proposal in the municipality of Rodolfo Fernandes/RN}

\begin{abstract}
The increase in the generation of solid waste caused by the world's population growth is one of the biggest problems faced today. Brazil has become the 3rd largest producer of solid waste in Latin America, this fact coupled to poor management efficiency and affecting all regions of the country has become one of the biggest obstacles in public management today. Before this reality, this work aimed to elaborate a proposal for the management of solid waste for the municipality of Rodolfo Fernandes/RN, covering from the stages of diagnosis to the proposals for actions. An exploratory study was performed based on research in official bodies, on technical documents, on-site visits and on data collection. A deficient management of municipal solid waste was diagnosed, with open-air waste disposal, and with an estimate of daily generation per capita below national and regional averages. The gravimetric composition showed a higher percentage of organic residues despite the values being considerably lower than the values presented nationally. It was also found that $20.44 \%$ of the waste is potentially recyclable, pointing to a situation of introducing the implementation of selective collection. The prognosis presented a scenario of the need for immediate adoption of changes in the final disposal of waste and the implementation of a waste collectors association that allows for a differentiated collection, also presenting strategic actions and executive measures for the management of solid waste in the municipality, in addition to practices that enable the dissemination of shared responsibility among the social actors involved. Finally, the lack of planning and management strategies for urban solid waste was highlighted, both in the operational phase and in the financial perception.
\end{abstract}

Keywords: Selective Collection; Gravimetric Composition; Solid Waste Management; Waste Collectors.

Topic: Engenharia Sanitária

Reviewed anonymously in the process of blind peer
Received: 05/09/2020

Approved: 10/11/2020
Ewerton Victor Pereira Mendonça (iD) Universidade Federal Rural do Semiárido, Brasil

http://orcid.org/0000-0001-7412-8603 ewerton.victor1404@gmail.com

Cláwsio Rogério Cruz de Sousa (it) Universidade Federal Rural do Semiárido, Universid

http://lattes.cnpq.br/5793812872780830 http://orcid.org/0000-0002-2778-5202 clawsio.cruz@ufersa.edu.br

Joel Medeiros Bezerra

Universidade Federal Rural do Semiárido, Brasil

http://lattes.cnpq.br/6945041178312614 http://orcid.org/0000-0002-8150-4125 joel.medeiros@ufersa.edu.br
Francisco Soares Roque (iD)

Universidade Federal Rural do Semiárido, Brasil http://lattes.cnpq.br/4466838919204802 http://orcid.org/0000-0003-3524-2344 fabiokand@gmail.com

Helves Clerverton Guerra Costa (iD

Universidade Federal Rural do Semiárido, Brasil http://lattes.cnpq.br/9052627585320406 http://orcid.org/0000-0002-4895-6840 helves.guerra5@gmail.com

\section{Talita Tássia da Costa (iD)}

Universidade do Estado do Rio Grande do Norte, Brasil

http://lattes.cnpq.br/0751541426540864 http://orcid.org/0000-0001-6912-8932 talitatcosta@hotmail.com
Samilly Brito Nobre (iD)

Universidade Federal Rural do Semiárido, Brasil

http://lattes.cnpq.br/5874088040659404 http://orcid.org/0000-0001-9915-1818 samillybritto2010@hotmail.com

\section{Antonia Patricia Dias Chaves (ID}

Universidade Federal Rural do Semiárido, Brasil

http://lattes.cnpq.br/0867635856160386 http://orcid.org/0000-0003-0802-5627 patricia.12325@hotmail.com

Ricassilly Isac Bruno Rufino Lima Universidade Federal Rural do Semiárido Brasil

http://lattes.cnpq.br/1677458778246978 http://orcid.org/0000-0002-6096-4827

ricassilly@hotmail.com
Denise Kauanny de Araújo Rosendo (ID Universidade Federal Rural do Semiárido, Brasil

http://lattes.cnpq.br/5381071947729146 http://orcid.org/0000-0002-2560-771X denise-kauany 12@hotmail.com
Referencing this:

MENDONÇA, E. V. P.; SOUSA, C. R. C.; BEZERRA, J. M.; ROQUE, F. S.; COSTA, H. C. G.; COSTA, T. T.; NOBRE, S. B.; CHAVES, A. P. D.; LIMA, R. I. B. R.; ROSENDO, D. K. A.. Proposta de gestão de resíduos sólidos do município de Rodolfo Fernandes/RN. Nature and Conservation, v.13, n.4, p.63-76, 2020. DOI: http://doi.org/10.6008/CBPC23182881.2020.004.0008 


\section{INTRODUÇÃO}

O crescimento da produção em massa a partir da revolução industrial trouxe como resultado para os dias atuais não apenas a alta no número de consumidores, mas também a crescente produção de Resíduos Sólidos Urbanos (RSU), o qual é um dos maiores problemas ambientais enfrentados na atualidade (MEDEIROS et al., 2019).

A partir de dados apresentados pela ONU (2017), nos países da América Latina, a geração diária de RSU atingiu 540 mil toneladas, no qual 30\% desse valor é destinado de forma inadequada. A expectativa para 2050 é que se atinja 671 mil toneladas por dia. O Brasil, não distante de tal realidade, é o 3o país maior produtor de RSU da América Latina, onde apenas 3\% é reciclado, embora 31\% são passíveis de reciclagem, que podem estar divididos entre seus tipos: vidros $(2,4 \%)$, são plásticos $(13,5 \%)$, papel e papelão $(13,1 \%)$ e metais (2,9\%) (SEBRAE, 2017).

Diante desse cenário foi instituído no Brasil a Política Nacional de Resíduos Sólidos (PNRS), através da Lei 12.305 de 2010, no qual dispõe os princípios, objetivos, instrumentos e diretrizes para uma gestão integrada de resíduos sólidos no país (BRASIL, 2010). A lei em apreço exalta a necessidade da determinação de metas que visem a redução, reutilização e reciclagem de resíduos, diminuindo a quantidade de rejeitos a serem encaminhados para a disposição final.

Em 2016 o Sistema Nacional de Informações sobre Saneamento - SNIS, realizou um levantamento em 3670 municípios brasileiros e conferiu que em 59,0\% desses municípios os RSU gerados são dispostos em aterros sanitários, 9,6\% em aterros controlados, 10,3\% em lixões, 3,4\% são levados para unidades de triagem e compostagem e 17,7\% sem informação a qual corresponde principalmente aos municípios com até 30 mil habitantes e parte da premissa que 3/4 desta "massa sem informação" é destinada a lixões (BRASIL, 2018).

O Nordeste brasileiro possui a segunda maior população do país, ficando atrás apenas do Sudeste (IBGE, 2017), no entanto, essa é uma região que foi historicamente menos favorecida, no tocante a investimentos públicos e privados, quando comparada a regiões com o Sul e Sudeste, o que levou a um comprometimento do seu desenvolvimento, inclusive referente ao saneamento básico. O SNIS estima que no Nordeste, cerca de 2,9\% da população encontra-se em situação de déficit de atendimento do serviço regular de coleta de Resíduos Domiciliares (RDO), isso representa a maior taxa de população urbana do Brasil não atendida pelo serviço, chegando a concentrar 44,7\% da população deficitária (BRASIL, 2018).

A Associação Brasileira de Empresas de Limpeza Pública e Resíduos Especiais - ABRELPE (2016), apontou no Panorama de Resíduos Sólidos no Brasil em 2016, que dos 1.794 municípios analisados na região Nordeste, $64,4 \%$ dos RSU são destinados para aterros controlados e lixões.

Dentro dessa realidade, insere-se o município de Rodolfo Fernandes, no interior do Rio Grande do Norte, localizado na região do Alto Oeste. O município conta com um manejo incorreto de resíduos e realiza a disposição final dos seus resíduos em um lixão, sem qualquer tratamento, metodologia incorreta segundo a Política Nacional dos Resíduos Sólidos - PNRS. Aliado a isso, a própria PNRS atribui ainda, prazos para o fim dos lixões e manejo ambientalmente adequado, prorrogados pelo Projeto de Lei no 425 de 2014, o que 
evidencia a imprescindibilidade de pesquisa acerca do assunto.

Neste contexto, se faz necessário um estudo local que explane os processos que englobam o manejo de resíduos sólidos, desde a limpeza dos logradouros até a destinação final dos resíduos, incluindo nisso a caracterização e quantificação dos mesmos, assim como, os aspectos socioeconômicos envolvidos e a caracterização da estrutura organizacional e econômica dos entes responsáveis pelo serviço de limpeza urbana.

O objetivo desse trabalho foi elaborar uma proposta de gestão de RSU para o município de Rodolfo Fernandes/RN, realizando um diagnóstico geral sobre a coleta, quantificação, composição e descarte dos resíduos gerados município.

\section{METODOLOGIA}

\section{Área de estudo}

O município de Rodolfo Fernandes, localizado no semiárido do Rio Grande do Norte, mesorregião do Alto Oeste Potiguar, na microrregião do Alto Oeste Potiguar, distante $371 \mathrm{~km}$ da capital Natal e a 55,7 km de Pau dos Ferros, cidade polo da microrregião do Alto Oeste, na qual esse se insere (Figura 1). A cidade está localizada numa área de $154,840 \mathrm{~km}^{2}$, equivalente a 0,29\% do território do Estado e sendo desses $8,5 \%$ encontrado na zona urbana (IBGE, 2019).

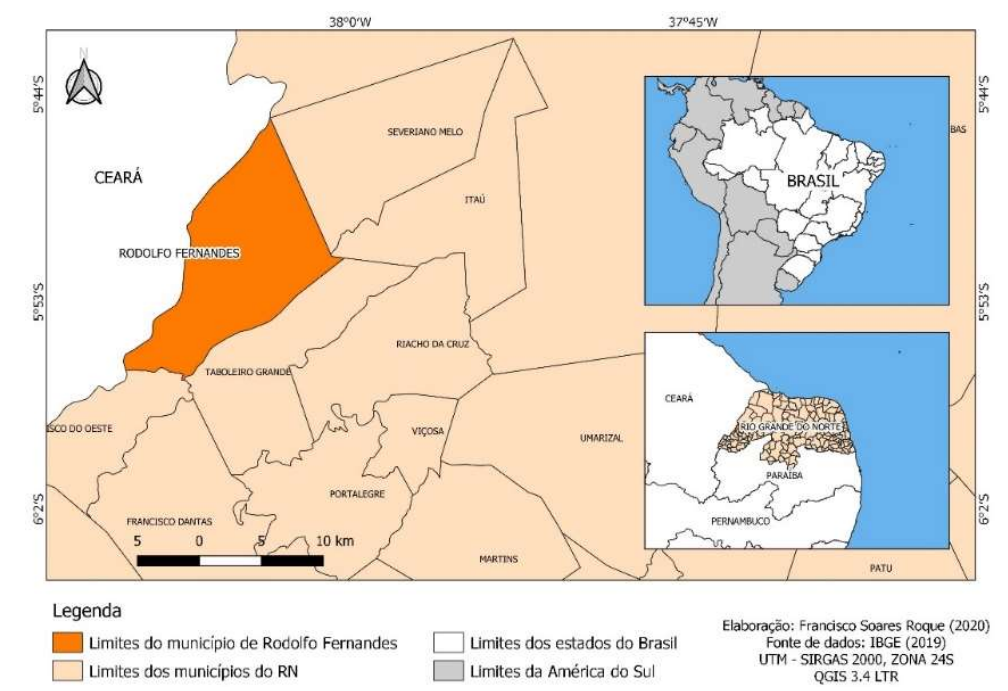

Figura 1: Localização da área de estudo do município de Rodolfo Fernandes/RN.

O município tem população estimada em 4472 pessoas, com 84,5 \% desta vivendo na zona urbana da cidade e possui sua economia baseada na agropecuária e setor de serviços, onde a agropecuária em 2015 representou 7,59 \% do PIB do município, enquanto o setor de serviços 21,17 \% do mesmo (IBGE, 2019).

\section{Procedimentos metodológicos}

A proposta de gestão integrada de resíduos sólidos no município de Rodolfo Fernandes se fundamentou, inicialmente, por meio de um diagnóstico da situação socioeconômica do município a partir do levantamento da situação de base, que se obteve informações históricas sobre o gerenciamento dos 
resíduos sólidos explorando algumas feições econômicas, sociais e ambientais.

A caracterização da produção dos resíduos se deu a priori por meio de levantamento de dados in loco e por pesquisas na Secretara Municipal de Infraestrutura e Meio Ambiente (SIMA) de Rodolfo Fernandes, como também visitas realizadas no vazadouro público, sendo possível a realização de entrevista semiestruturada com catadores de materiais recicláveis que fazem a coleta desses resíduos no local, além do levantamento georreferenciado do local de estudo, como também análise quali-quantitativa dos resíduos.

A realização do levantamento georreferenciado da área do vazadouro foi feito através de GPS $78 \mathrm{H}$ da Garmin, assim como, a identificação e delimitação dos corpos hídricos mais próximos do vazadouro e dos locais onde, anteriormente, eram realizados a disposição final do resíduo (os antigos vazadouros desativados), como também da rodovia mais próxima. Foram identificadas as coordenadas de GPS pelo sistema UTM e inseridas no software QGIS para levantamento dos pontos coletados.

A Figura 2 mostra as áreas compreendidas das três rotas de coleta dos resíduos do município, que ocorrem de forma alternada em dois dias da semana que foi possível coletar dados representativos nas rotas com maior área residencial e comercial.

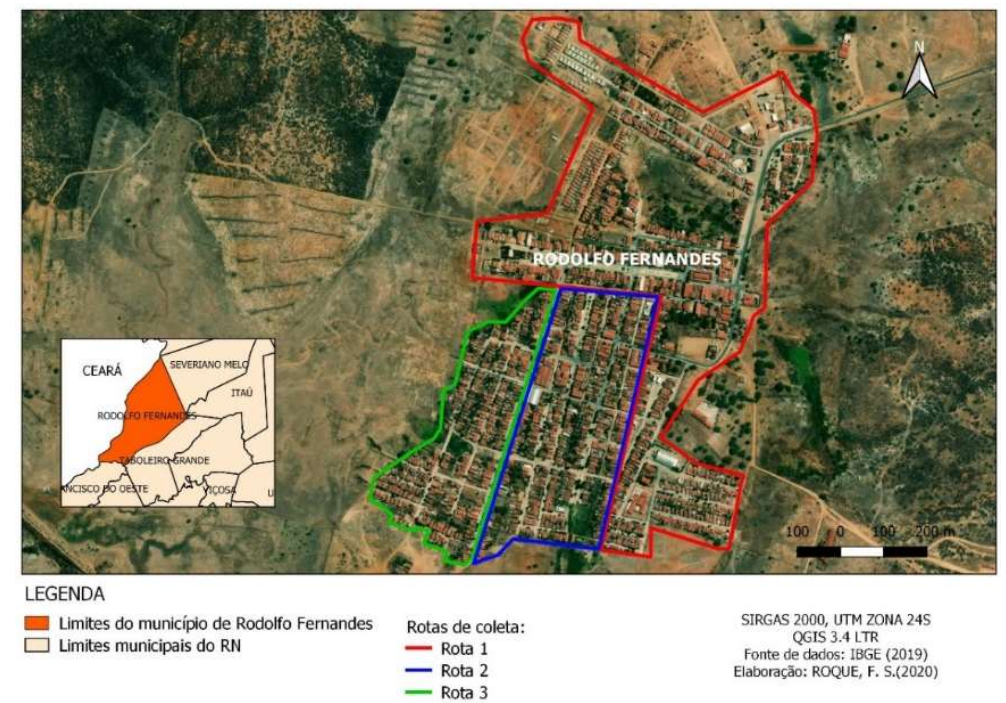

Figura 2: Área de abrangência das rotas de coleta de resíduos sólidos de Rodolfo Fernandes/RN.

A obtenção das amostras para a caracterização qualiquantitativa dos resíduos que chegam ao vazadouro público foi realizada por meio do método do quarteamento. Fazendo-se adaptação do método segundo Alkmin et al. (2017), que após a descarga dos resíduos pelo caminhão coletor, são retiradas 5 amostras de 20 litros da pilha, sendo 1 no topo e 4 na base da mesma (Figura 3 A). Depois de coletadas, as amostras são depositadas na lona (Figura 3 B), em que são abertos os sacos plásticos e os materiais são homogeneizados com auxílio de uma pá ou enxada. Em seguida, é realizado o quarteamento da mesma (Figura 3 C), sendo separada e descartada uma das diagonais. Posteriormente é segregado o material nas seguintes categorias: Matéria Orgânica, Papel/Papelão, Plástico, Metal, Vidro, Tecido, Madeira, Resíduos de parques e jardins, Resíduos de serviço de saúde e Rejeitos, e feita a pesagem de cada tipo de material (Figura $3 \mathrm{D})$. 


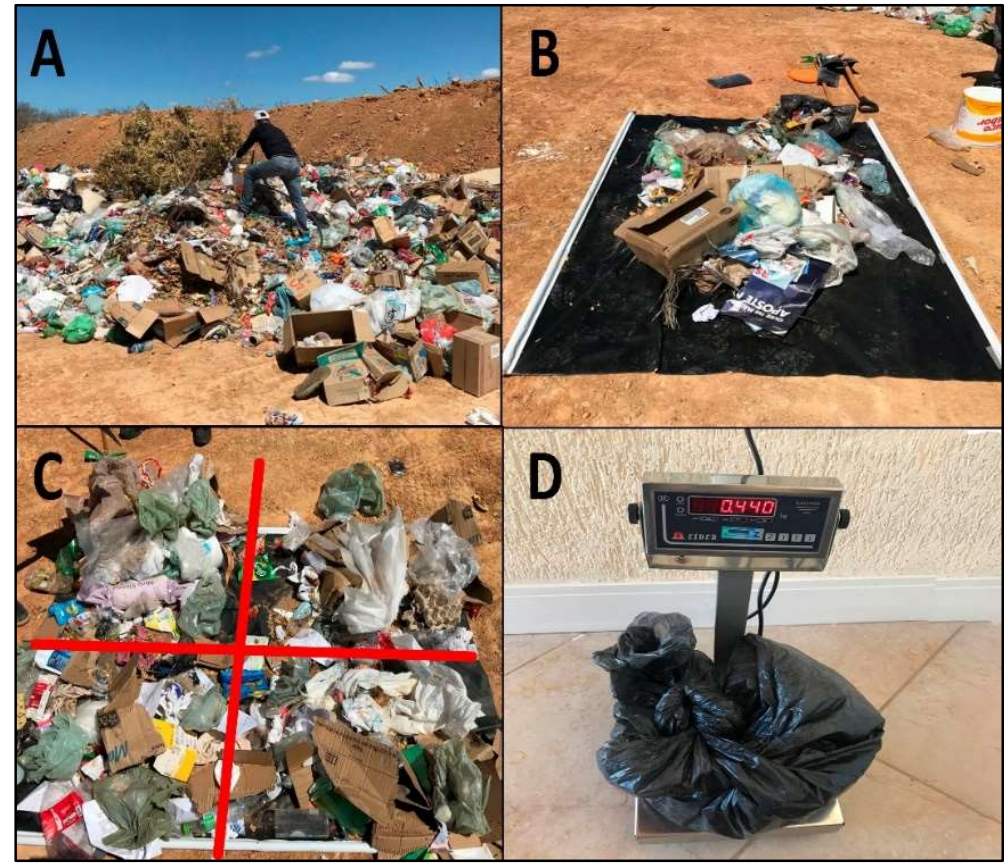

Figura 3: Procedimento de gravimetria dos RSU no vazadouro- público de Rodolfo Fernandes/RN: A) Coleta das amostras, B) Amostras homogeneizadas e dispostas na lona, C) Divisão da amostra em quatro partes iguais e D) Pesagem de cada tipo de material separado.

A quantificação dos resíduos sólidos gerados diariamente por veículo foi realizada através de extrapolação dos dados encontrados das amostras coletadas no vazadouro. Foram somadas as massas de todos os materiais coletados, chegando assim, a massa total coletada. Sabendo-se o volume das amostras coletadas chegou-se a uma massa especifica dos resíduos depositados no vazadouro público municipal. Multiplicando esse resultado pela estimativa de geração volumétrica diária da cidade, encontrou-se a estimativa em massa de resíduos sólidos gerados diariamente. Posterior a isso foi calculado a geração per capita diária dividindo-se o resultado encontrado a estimativa da população.

Diante do diagnóstico elaborado da situação atual da área de estudo e averiguação da legislação vigente foi possível elaborar um prognostico de possíveis impactos ocasionados pela continuação do atual manejo dos resíduos sólidos no município, nessa etapa se averiguou a estimativa de vida útil das células do vazadouro. Com as medições de área e altura útil das células, chegou-se ao volume de utilização das mesmas, sendo posteriormente dividido pelo volume gerado diariamente para se encontrar a vida útil do dispositivo. Além disso, elaborou-se proposições de ações que possam mitigar os efeitos já detectados, assim como, propor um novo manejo dos resíduos e uma destinação final ambientalmente adequada, visando alterar o cenário atual de degradação.

\section{RESULTADOS E DISCUSSÃO}

\section{Diagnóstico}

\section{Características gerais da produção dos RSU}

Considerando as informações sobre a produção e gerenciamento de Resíduos Sólidos Urbanos (RSU) fornecidas pelos órgãos municipais, procedeu-se a quantificação e caracterização dos mesmos. A estimativa 
da massa diária de resíduos se deu pelo acompanhamento dos caminhões de coleta municipal em que se verificou o valor médio aproximado de $2.385 \mathrm{~kg} / \mathrm{dia}$. Considerando a estimativa da população do município, a geração per capita foi calculada em 0,530 kg/habitante/dia. Este valor é muito inferior à média nacional, estimada em 1,039 kg/habitante/dia, sendo inferior também a média nordestina, estimada em 0,951 $\mathrm{kg} /$ habitante/dia (ABRELPE, 2019). Realizada a composição gravimétrica de RSU do município, chegou-se aos resultados expressos na Figura 4.

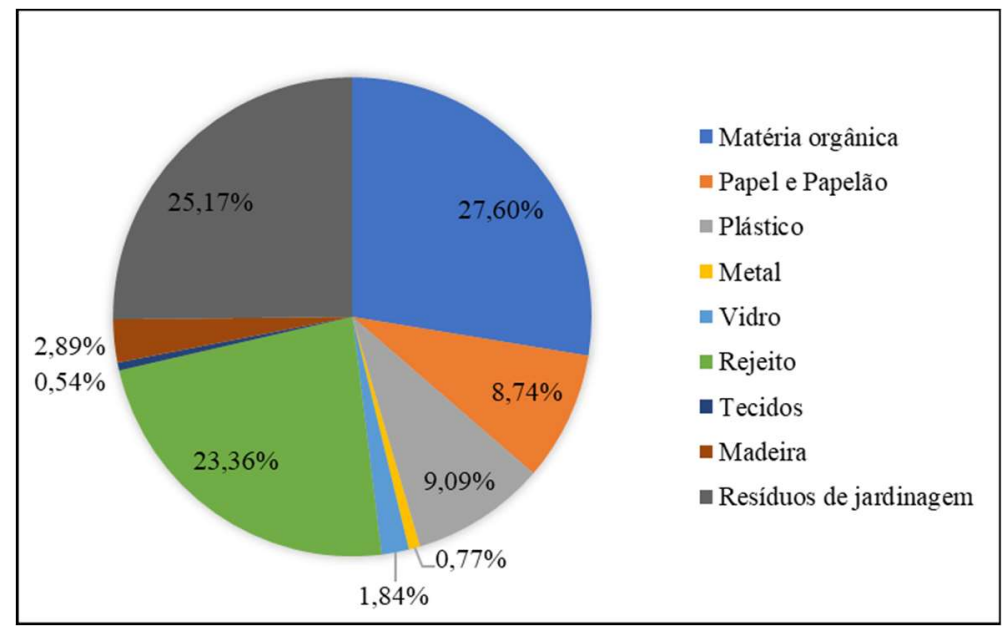

Figura 4: Composição gravimétrica dos RSU de Rodolfo Fernandes/RN.

De acordo com a Figura 04 a fração orgânica foi a mais significativa, com 27,35\%, porém muito inferior à média nacional, que é de 52,5\% (DOMINGOS et al., 2015). Uma possível explicação para este resultado deve-se ao hábito de reuso da fração orgânica dos RSU para a alimentação animal, principalmente de galinhas e porcos, culturas muito comuns entre os habitantes locais. Este resultado corrobora com o baixo valor da geração per capita de RSU no município, já que a destinação da fração orgânica adotada pela população de Rodolfo Fernandes foi responsável pela redução do mais significativo componente disposto no vazadouro municipal. É importante observar que os resíduos de jardinagem (25,17\%), podem ser classificados como resíduos orgânicos, porém foram avaliados separadamente devido à coleta e disposição diferenciada de RSU realizada pelo sistema de coleta municipal. O significativo percentual de resíduos de jardinagem foi justificado pela periodicidade em que é realizado a coleta deste material, que ocorre de maneira quinzenal, de acordo com a Secretaria de Infraestrutura municipal.

O alto percentual de rejeitos, com $23,36 \%$, foi esperado por não haver coleta seletiva ou segregação de RSU na fonte geradora, resultando em quantidade considerável de materiais contaminados que poderiam ser enquadrados em outras categorias, como papel e papelão que facilmente se contaminam com resíduos orgânicos, por exemplo. Nessa perspectiva, entre as vantagens obtidas pela implementação de metodologias de coleta seletiva, destaca-se a redução de custos com a triagem, lavagem e secagem dos resíduos, resultantes da segregação previa e da diminuição de materiais contaminados presentes no lixo (MIRANDA et al., 2018). No contexto nacional, a Resolução $n^{\circ} 275$ do Conselho Nacional do Meio Ambiente (CONAMA), de abril de 2001, estabelece o código de cores para identificação de coletores e transportadores para cada tipo de resíduo e define o padrão a ser seguido em programas de coleta seletiva. 
Os materiais como metal, papel e papelão, plástico e vidro, que juntos totalizaram 20,44\%, apresentam-se individualmente com baixo percentual devido à ação de catadores de materiais recicláveis que atuam previamente na área urbana, tal como ainda na área do vazadouro. Sabedot et al. (2017), que analisaram o desempenho ambiental dos catadores de materiais recicláveis no município de Esteio (RS), identificaram diversos materiais (papel e papelão, plásticos, vidro, eletroeletrônicos e metais, como alumínio, sucata de ferro, cobre) com diferentes graus de atratividade para os catadores na composição gravimétrica dos resíduos sólidos recicláveis coletados por estes trabalhadores. Os autores estimaram a massa média individual de recicláveis coletados em $1.200 \mathrm{~kg} / \mathrm{mês}$, evidenciando a importância e o impacto da atuação desses profissionais. Em Rodolfo Fernandes, o volume de resíduos destinados à reciclagem pelos catadores, apesar de não quantificado neste trabalho, é considerado como significativo na perspectiva de um município de pequeno porte, como se observa na Figura 5.

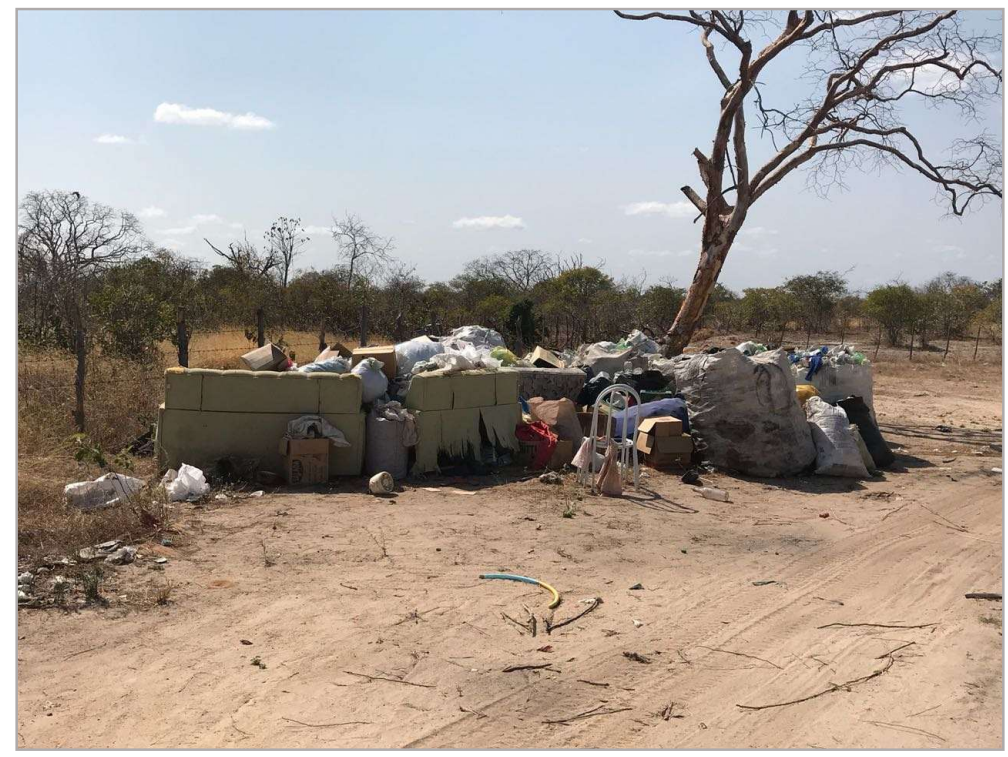

Figura 5: Material reciclável segregado e coletado por catadores no vazadouro-público de Rodolfo Fernandes/RN.

Com as visitações ao vazadouro e entrevistas realizadas junto aos órgãos municipais, foram identificados quatro catadores em atividade: um catador cadastrado junto à prefeitura que realiza a coleta no vazadouro, e três catadores que trabalham no centro urbano. Conforme a Política Nacional de Resíduos Sólidos (PNRS), instituída pela Lei 12.305 de 2010, a plena efetivação da gestão integrada dos resíduos sólidos somente ocorre com a valorização do papel desempenhado por esta classe de trabalhadores, estando eles diretamente relacionados aos princípios de reutilização e reciclagem, como também integrados nos processos de logística reversa e coleta seletiva (BRASIL, 2010).

No vazadouro foram identificados os mais diversos resíduos (Figura 6). Destaca-se a disposição dos classificados como perigosos, como Resíduos de equipamentos eletroeletrônicos (REEE), carcaças de animais provenientes do matadouro público municipal e resíduos hospitalares. Por apresentar riscos à saúde pública e ao meio ambiente, os resíduos perigosos, que são classificados segundo NBR 10.004 (ABNT, 2004), devem ser submetidos a logística reversa, com o produtor responsável pela sua destinação ambientalmente adequada, conforme a legislação vigente (PNRS). 


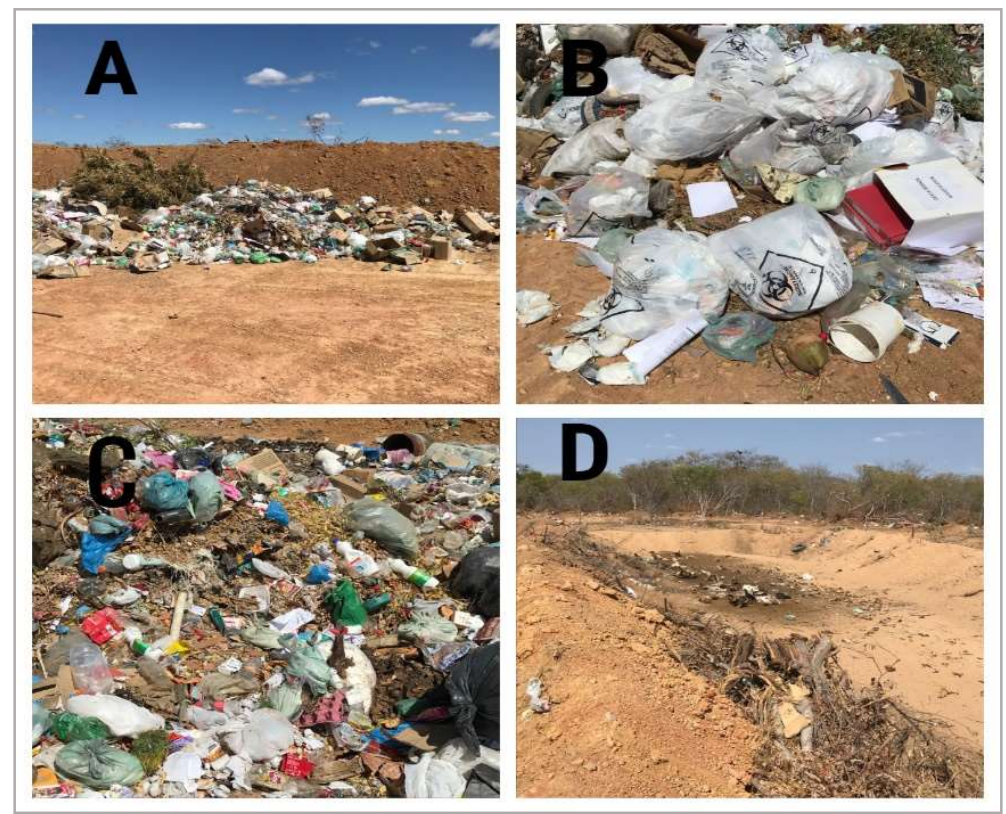

Figura 6: Resíduos encontrados no vazadouro de Rodolfo Fernandes: A) RSU e Resíduos de poda, B) Resíduos Hospitalares, C) RSU e D) Resíduos do matadouro público.

\section{Características gerais do tratamento e destinação final do RSU}

A destinação final de RSU realizada no município ocorre em vazadouro a céu aberto sem qualquer tratamento. Em entrevista com o gestor local, foi afirmado que questões econômicas e burocráticas são os principais fatores que impedem a ampliação da gestão dos resíduos da cidade. O mesmo ainda destacou o andamento das negociações para ingresso do município no consórcio da gestão dos resíduos sólidos do Alto Oeste, havendo, segundo o prefeito, previsão para que nos próximos anos o aterro sanitário do consórcio passe ser a destinação dos RSU do município.

Urban (2016) destaca que municípios de pequeno porte, com restrições financeiras, são os que mais enfrentam problemas para adequação da disposição de resíduos no Brasil. O autor sugere a adoção de aterros sanitários comuns, implementados através de consorcio de cidades, como alternativa de destinação por possibilitarem reduções de custos.

A PNRS define os aterros sanitários como os mecanismos de disposição final ambientalmente adequada (BRASIL, 2010). Desta forma, pode-se entender os aterros controlados como uma 'solução temporária', já que oferecem algum tipo de controle e remediação na disposição dos resíduos, porém não atendem todas as diretrizes e princípios de engenharia previstas pela PNRS, como a coleta e tratamento de percolado e gases e a impermeabilização do solo.

Segundo informado pela secretaria municipal de infraestrutura de Rodolfo Fernandes historicamente, o descarte de materiais realizou-se, em diferentes localidades, ao longo do tempo, em terrenos públicos e particulares, implicando na possibilidade de contaminação do solo e dos recursos hídricos da região. Sendo as mudanças de localização do vazadouro a céu aberto municipal motivadas por razões políticas, consequentemente tornando inviável qualquer uso do solo nos locais utilizados para este fim.

Esta realidade persistiu até o ano de 2017, quando se passou a utilizar o vazadouro a céu aberto 
municipal de Itaú, uma cidade vizinha, para destinação conjunta dos resíduos. Em 2018 a disposição de RSU passou a ocorrer no sítio Tanque do Angico, na zona rural de Rodolfo Fernandes, distante 13 Km do centro da cidade, permanecendo como principal via de destinação de RSU atualmente. A Figura 7 destaca as localizações dos vazadouros de resíduos sólidos, bem como, de corpos hídricos próximos.

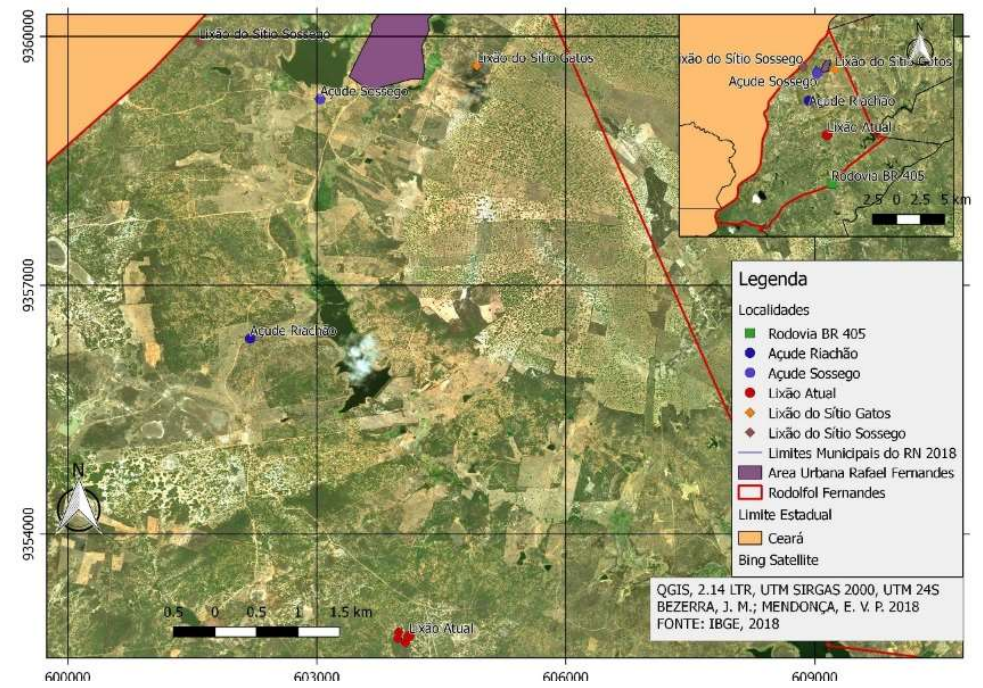

Figura 7: Localização dos dispositivos de vazadouros de RSU existentes de Rodolfo Fernandes.

Na Figura 7 foi possível observar a proximidade de dois dos antigos vazadouros (Lixão do Sítio Gatos e Lixão do Sítio Sossego) à um dos corpos hídricos da região (Açude Sossego). Neste caso, ficou evidente a importância do sistema de gestão de resíduos sólidos, já que este documento leva em consideração os impactos ocasionados pela localização do destino final, de forma a minimizar seus efeitos sobre o ambiente natural e urbano (MANNARINO et al., 2016). Segundo Mannarino et al. (2016) a definição do local de destinação final dos resíduos deve considerar diferentes critérios de proteção do ambiente natural e urbano, levando em consideração aspectos da hidrologia, área ocupada pelos resíduos, degradação do entorno, tempo para reutilização da área, entre outros.

Silva et al. (2018) avaliaram a contaminação da água por metais pesados no açude público do município de Teofilândia/BA, localizado em área de influência do vazadouro local. A análise da água indicou que alguns dos metais pesados avaliados como chumbo $(\mathrm{Pb})$, cobre $(\mathrm{Cu})$, manganês $(\mathrm{Mn})$ e níquel $(\mathrm{Ni})$ apresentavam-se com concentrações superiores à concentração máxima estabelecida pela Resolução CONAMA 357/2005, na maioria dos períodos e pontos considerados. Este resultado indicou que a proximidade dos antigos lixões ao Açude Sossego é preocupante, sendo necessário investigar sua influência sobre a qualidade da água.

O atual vazadouro a céu aberto municipal possui área de $9.647 \mathrm{~m} 2$ e não apresenta qualquer estrutura de drenagem de percolado ou captação de biogás. Por meio de visitas in loco foi verificado que as únicas medidas paliativas realizadas no vazadouro foram à disposição segregada de alguns tipos de resíduos em células, a preparação do solo para a disposição dos resíduos e o cercamento da área para barrar a entrada de pessoas não autorizadas. A disposição ocorre em quatro células que recebem, separadamente, resíduos da construção civil, podas e capinas, resíduos domiciliares e os resíduos provenientes do matadouro púbico 
municipal, conforme se visualiza na Figura 8.

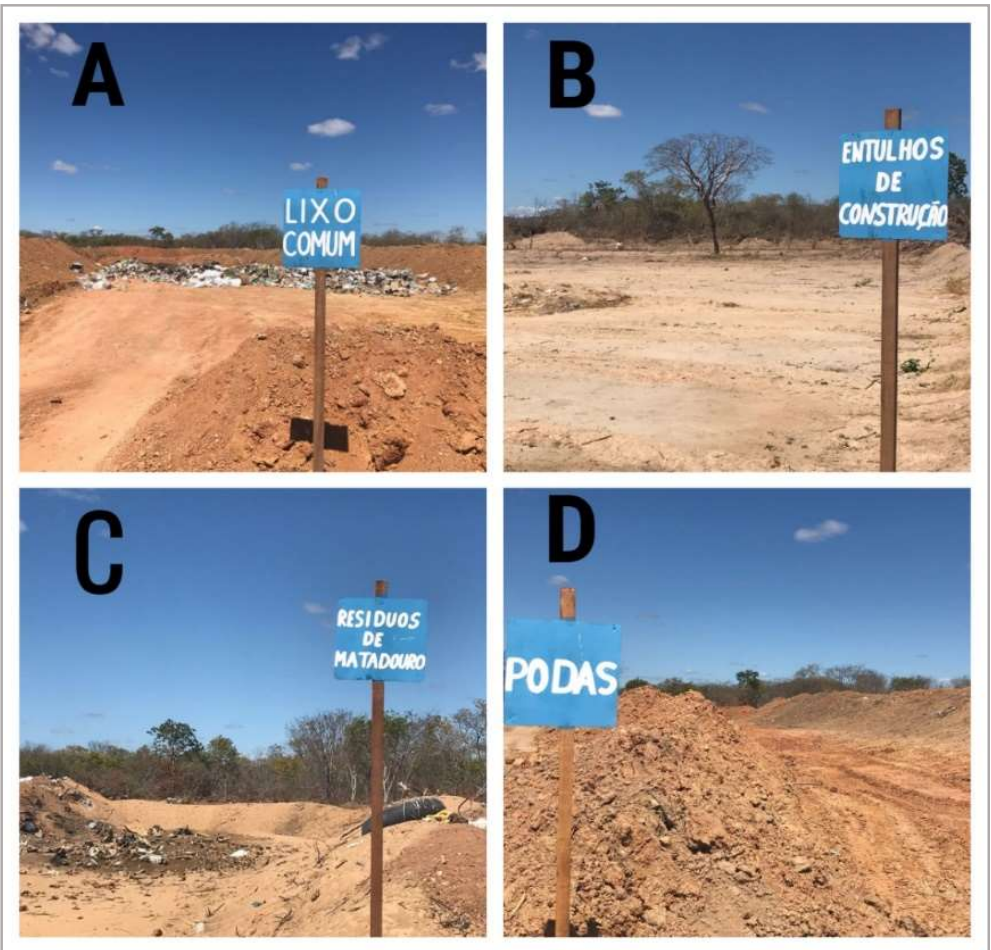

Figura 8: Disposição diferenciada de RSU por célula no vazadouro de Rodolfo Fernandes/RN: A) Célula para os resíduos domiciliares, B) Célula para os resíduos da construção civil, C) Célula para os resíduos do matadouro municipal e D) Célula para podas e capinas.

A preparação do solo para o recebimento dos resíduos ocorre quinzenalmente, com a compactação e o recobrimento com solo argiloso, realizado por uma retroescavadeira. Para controle do volume dos resíduos depositados nas células são realizadas queimas semanais dos materiais. A queima dos RSU e de resíduos de serviços de saúde sem a adoção de medidas de controle, causam a emissão de dioxinas e furanos ao ambiente, compostos com alto potencial tóxico e persistência que compromete severamente a qualidade ambiental e põe em risco a saúde pública (ASSUNCAO et al., 1999). Os atores mais vulneráveis neste quadro são os catadores de materiais recicláveis, que ficam expostos diariamente, não só ao resíduo perigoso, como também, aos novos compostos altamente tóxicos gerados pela medida de controle de volume de RSU no vazadouro municipal.

\section{Prognóstico}

De acordo com a estimativa do Instituto Brasileiro de Geografia e Estatística - IBGE (2010), o município em estudo tem registrado um relativo crescimento tanto populacional quanto na geração per capita entre os anos 2010 e 2019. Portanto, esses fatores quando aliados influenciam diretamente na importância do gerenciamento adequado de RSU, já que os mesmos variam quanto a quantidade, tipo e impactos ao meio (NASCIMENTO et al., 2015).

Segundo Azevedo et al. (2015), com a relação entre o crescimento populacional e áreas de influência define-se o risco do vazadouro. Diante desta análise, comprova-se a presença de impactos negativos no âmbito social, econômico e ambiental, que são acarretados preponderantemente devido disposição 
inadequada dos resíduos num grande período de tempo e sem tratamento adequado.

Os resíduos de construção civil, poda e capina classificados de acordo com a PNRS como RSU são comumente dispostos com outros, ou seja, dependendo do quantitativo gerado e forma de descarte influenciam diretamente na capacidade destas áreas (ARAÚJO et al., 2019; RODRIGUES et al., 2015). Então, com o volume insuficiente encontrado dos mesmos nas suas células (Figura 8), especificas do local de estudo não se pode estimar vida útil e prospecções destas.

Segundo Siqueira et al. (2016) os resíduos orgânicos devem ser previamente separados e posteriormente utilizados como compostagem, pois quando dispostos de forma inadequadas podem liberar gases, aumentar a produção de chorume e comprometer a reutilização dos demais. No estudo evidencia a presença de uma grande quantidade resíduos orgânicos sem separação, sendo misturados com os potencialmente recicláveis.

De acordo com a Prefeitura Municipal de Rodolfo Fernandes, diante o crescimento no volume gerado, o município vem investindo parte de suas receitas no manejo dos resíduos sólidos, já que ainda não exista receita especifica para esse fim. Assim, o crescimento populacional e a maior demanda por produtos industrializados, resultará em uma maior geração de resíduos como também o aumento contínuo nos gastos com seu manejo (CÉSAR, 2018).

Segundo Francischetto et al. (2016) é imprescindível que os catadores sejam organizados em associações ou cooperativas para garantir condições de trabalho adequado, melhor logística dos materiais e eficiência na implantação da coleta seletiva. Só que através do levantamento in loco evidenciou-se a presença de poucos catadores e nenhuma associação ou cooperativa, ou seja, cenário que denota que pouco há de se ganhar ou evoluir no que tange segregação dos materiais e beneficiamento dos resíduos.

\section{Plano de ação}

Segundo Nascimento et al. (2018) após o diagnóstico e prognóstico deve se estabelecer a implementação de um plano de ações que busque solucionar os problemas encontrados, assim como, prevenir futuras complicações que venham a ocorrer em decorrência gestão ineficiente. Na figura 9 é explanado a proposta dessa ação para o município de Rodolfo Fernandes diante os estudos analisados previamente.

A responsabilidade compartilhada consiste em atribuir obrigações a quem produz e gera os resíduos, ou seja, são atribuídos a ambos deveres quanto a essa gestão para que exista uma maior eficiência (GARCIA et al., 2016). Portanto se faz imprescindível delimitar as atribuições de cada ator social, seja público ou privado, devendo contemplar os geradores através de ações como o cadastro de empreendimentos, fiscalização efetiva, descarte e destinação do RSU de acordo com PNRS.

De acordo com Rhoden et al. (2018) a sensibilização ambiental consegue promover uma sociedade participativa e inclusiva na construção e execução do Gerenciamento dos Resíduos Sólidos, onde são capazes construir conjuntamente estas ações. Então diante do cenário faz-se necessário promover a conscientização 
da população como também promover a descentralização de informações com boletins e assembleias públicas sobre a temática do saneamento básico que está diretamente interligado com qualidade de vida.

\begin{tabular}{|c|c|}
\hline $\begin{array}{l}\text { Definir } \\
\text { responsabilidades }\end{array}$ & $\begin{array}{c}\text { •Público e privado; } \\
\text { - Coleta, destinação e tratamento } \\
\text { do RSU. }\end{array}$ \\
\hline $\begin{array}{c}\text { Garantir informação } \\
\text { sobre GRS }\end{array}$ & $\begin{array}{l}\text {-Promoção de assembleias } \\
\text { públicas; } \\
\text { •Boletins informativos. }\end{array}$ \\
\hline $\begin{array}{c}\text { Ações de } \\
\text { conscientização }\end{array}$ & $\begin{array}{l}\text { - Campanhas de sensbilização e } \\
\text { educação ambiental em escolas, } \\
\text { comunidades e outros. }\end{array}$ \\
\hline Criação de comitê & $\begin{array}{l}\text {-Elaborar, execultar e fiscalizar o } \\
\text { lano de GRS no município. }\end{array}$ \\
\hline $\begin{array}{l}\text { Gerenciamento de } \\
\text { RSU }\end{array}$ & $\begin{array}{l}\text { - Implantação da coleta seletiva, } \\
\text { local adequado para destinação e } \\
\text { organização do sistema de GRS. }\end{array}$ \\
\hline
\end{tabular}

Figura 9: Proposta do Plano de ação do município de Rodolfo Fernandes/RN.

O PGRS contém ações e estratégias que fortalecem esse serviço no local que são desde mudanças nas rotas de coleta para diminuição do custo com combustível a capacitações dos envolvidos no processo. Então propõe-se que o mesmo tenha metas e prazos para que sejam cumpridos, levando sempre em consideração a política nacional dos resíduos sólidos e a viabilidade socioeconômica da área.

Como se pode verificar, o município não conta com associação de catadores de materiais recicláveis e há poucas pessoas que trabalhem diretamente com esses materiais então faz se necessário o fortalecimento deste setor. Já que segundo as diretrizes da PNRS inciso XII do art. 7, a importância da integração dos catadores de materiais recicláveis nas ações que envolvam a responsabilidade compartilhada pelo ciclo de vida do produto (BRASIL, 2010).

Pode se verificar ainda que somente $7,2 \%$ da mão de obra é empregada formalmente e $23,87 \%$ dos resíduos gerados são levados até o vazadouro sendo potencialmente reutilizáveis ou recicláveis, o que potencializa a necessidade de um plano de ação com a inserção dos catadores de materiais recicláveis, para que se possa ter não apenas uma redução de material descartado, mas também, um avanço social de pessoas de baixa renda (IBGE, 2010).

\section{CONCLUSÕES}

Com uma estimativa de produção per capita de resíduos sólidos de $0,53 \mathrm{~kg} / \mathrm{hab} / \mathrm{dia}$ e uma área de destinação com pouco tempo de utilização, o qual apresenta o dispositivo de um aterro controlado, atrelado a uma condição de manejo inadequado, constata-se a necessidade de uma gestão diferenciada e integrada dos resíduos sólidos, a qual se torna cada vez mais evidente.

Considerando ainda que a PNRS impõe o fim dos lixões, de acordo com o projeto de lei do senado no 425 de 2014, para o fim de 2021, cabe ao município implementar uma gestão integrada e criar um local de 
disposição final ambientalmente adequado, em consonância com a lei, sendo a solução consorciada a mais viável técnica e financeiramente, mas que não sendo possível sua realização em curto prazo, o município deverá planejar e executar medidas paliativas de controle ambiental.

Por fim, são necessários estudos mais aprofundados sobre o solo e hidrogeologia do local onde está localizado o vazadouro, assim como, o conhecimento aprofundado acerca de todos os princípios e diretrizes para uma eficiente gestão integrada dos resíduos sólidos, tal como avaliação do cenário de contaminação das áreas desativadas de vazadouros do município.

\section{REFERÊNCIAS}

ABNT. Associação Brasileira de Normas Técnicas. NBR 10004:2004 Resíduos Sólidos: Classificação. Brasil: ABNT, 2004.

ABRELPE. Associação Brasileira de Empresas de Limpeza Pública e Resíduos Especiais. Panorama dos resíduos sólidos no Brasil - 2016. São Paulo: ABRELPE, 2016.

ABRELPE. Associação Brasileira de Empresas de Limpeza Pública e Resíduos Especiais. Panorama dos Resíduos Sólidos no Brasil 2018/2019. São Paulo: ABRELPE, 2019.

ALKMIN, D. V.; RIBEIRO JUNIOR, L. U.. Determinação da composição gravimétrica dos resíduos sólidos urbanos (RSU) do lixão do município de Maria da Fé, estado de Minas Gerais. Caminhos de Geografia, Uberlândia, v.18, n.61, p.65-82, 2017. DOI: https://doi.org/10.14393/RCG186105

ARAÚJO, L. G. S.; LEAL JÚNIOR, C. R. M.; AMORIM, E. L. C.; SILVA, J. A.. Gestão de resíduos sólidos urbanos: um diagnóstico dos municípios do Sertão Alagoano. Revista Gestão \& Sustentabilidade Ambiental, v.8, n.1, p.483-516, 2019. DOI: https://doi.org/10.19177/rgsa.v8e12019483-516

ASSUNCAO, J. V.; PESQUERO, C. R.. Dioxinas e furanos: origens e riscos. Revista de Saúde Pública, São Paulo, v.33, n.5, p.523-530, 1999. DOI: https://doi.org/10.1590/S0034-89101999000500014

AZEVEDO, P. B.; LEITE, J. C. A.; OLIVEIRA, W. S. N.; SILVA, F. M.. Diagnóstico da degradação ambiental na área do vazadouro de Pombal, PB. Revista Verde de Agroecologia e Desenvolvimento Sustentável, v.10, n.1, p.20-34, 2015.

BRASIL. Lei $\mathbf{n . ~ 1 2 3 0 5 , ~ d e ~} \mathbf{2}$ de agosto de 2010. Institui a Política Nacional de Resíduos Sólidos; altera a Lei no 9.605, de 12 de fevereiro de 1998; e dá outras providências. Brasília: DOU, 2010.

BRASIL. Ministério das Cidades. Secretaria Nacional de Saneamento Ambiental - SNSA. Sistema Nacional de Informações sobre Saneamento - SNIS: Diagnóstico do Manejo de Resíduos Sólidos Urbanos - 2016. Brasília: MCIDADES.SNSA, 2018.

CÉSAR, P. S. M.. Reflexões sobre a qualidade do gasto público na gestão de resíduos sólidos urbanos. Revista da CGU, Distrito Federal, v.10, n.17, p.980-1.004, 2018.
CONAMA. Conselho Nacional do Meio Ambiente. Resolução n. 275, de $\mathbf{2 5}$ de abril de 2001. Estabelece o código de cores para os diferentes tipos de resíduos, a ser adotado na identificação de coletores e transportadores, bem como nas campanhas informativas para a coleta seletiva. Brasília: CONAMA, 2001

CONAMA. Conselho Nacional do Meio Ambiente. Resolução n. 357, de 17 de março de 2005. Dispõe sobre a classificação de corpos de água e normas ambientais para o seu enquadramento, bem como determina as condições e padrões de lançamento de efluentes e fornece outras providências. Brasília: CONAMA, 2005

DOMINGOS, D. C.; BOEIRA, S. L.. Gerenciamento de Resíduos Sólidos Urbanos Domiciliares: análise do atual cenário no município de Florianópolis. Revista de Gestão Ambiental e Sustentabilidade, v.4, n.3, p.14-30, 2015. DOI: http://dx.doi.org/10.5585/geas.v4i3.275

FRANCISCHETTO, G. P. P.; PINHEIRO, P. T.. A política nacional de resíduos sólidos como mecanismo de fortalecimento das associações de catadores de materiais recicláveis. Derecho y Cambio Social, Lima, v.43, n.1, p.1-24, 2016.

GARCIA, M. B. S.; LANZELLOTTI NETO, J.; MENDES, J. G.; XERFAN; F. M. F.; VASCONCELLOS, C. A. B.. Resíduos sólidos: responsabilidade compartilhada. Semioses, v.9, n.2, p.77-91, 2016. DOI:

http://dx.doi.Org/10.15202/1981996X.2015v9n2p77

IBGE. Instituto Brasileiro de Geografia e Estatística. Panorama dos municípios. Rio de Janeiro: IBGE, 2010.

IBGE. Instituto Brasileiro de Geografia e Estatística. Estimativas de população - 2018. Rio de Janeiro: IBGE, 2017.

IBGE. Instituto Brasileiro de Geografia e Estatística. Pesquisa de Informações Básicas Municipais. Rio de Janeiro: IBGE, 2019.

MANNARINO, C. F.; FERREIRA, J. A.; GANDOLLA, M.. Contribuições para a evolução do gerenciamento de resíduos sólidos urbanos no Brasil com base na experiência Europeia. Engenharia Sanitária e Ambiental, Rio de janeiro, v.21, n.2, p.379-385, 2016. DOI: http://dx.doi.org/10.1590/s1413-41522016146475 
MEDEIROS, A. S.; AMORIM, M. C.; MELO, M. D. C. A.; SOUZA, M. A.; NASCIMENTO, V. X.. Correlação de indicadores socioeconômicos e a geração de resíduos sólidos urbanos do município de Atalaia, Alagoas, Brasil. Brazilian Journal of Animal and Environmental Research, v.2, n.6, p.1896-1900, 2019.

MIRANDA, N. M.; MATTOS, U. A. O.. Revisão dos modelos e metodologias de coleta seletiva no Brasil. Revista Sociedade \& Natureza, Uberlândia, v.30, n.2, p.1-22, 2018. DOI: https://doi.org/10.14393/SN-v30n2-2018-1

NASCIMENTO, R. M.; PINTO, A. E. M.. Sustentabilidade e precaução: uma avaliação do plano municipal de gerenciamento de resíduos de Macaé referenciados na Política Nacional de Resíduos Sólidos. Revista de Direito da Cidade, v.10, n.1, p.78-94, 2018. DOI:

https://doi.org/10.12957/rdc.2018.29600

NASCIMENTO, V. F.; SOBRAL, A C.; ANDRADE, P. R.; OMETTO, J. P. H. B.. Evolução e desafios no gerenciamento dos resíduos sólidos urbanos no Brasil. Revista Ambiente \& Água, v.10, n.4, p.889-902, 2015. DOI: https://doi.org/10.4136/ambi-agua.1635

ONU. Organização das Nações Unidas. ONU: América Latina e Caribe despejam $\mathbf{3 0} \%$ de seu lixo em locais inadequados. Nações Unidas: Brasil, 2017.

RHODEN, V.; RIBEIRO, L. B.; SALOMONI, S. E.. Relatos de atividades de conscientização e educação ambiental sobre o destino correto dos resíduos sólidos em São Borja/RS. Extensio: Revista Eletrônica de Extensão, Florianópolis, v.15, n.28, p.77-86, 2018.
RODRIGUES, P. R. B.; PICANÇO, A. P.; SERRA, J. C. V.; GUARDA, E. A.; LIMA JUNIOR, A. S.. Análise do potencial de reutilização dos resíduos provenientes de poda, município de Palmas, Tocantins. Revista Ibero-Americana de Ciências Ambientais, v.6, n.1, p.269-284, 2015. DOI: https://doi.org/10.6008/SPC2179-6858.2015.001.0021

SABEDOT, S.; PEREIRA NETO, T. J.. Desempenho ambiental dos catadores de materiais recicláveis em Esteio (RS). Engenharia Sanitária e Ambiental, Rio de Janeiro, v.22, n.1, p.103-109, 2017. DOI: https://doi.org/10.1590/s1413-41522016155686

SEBRAE. Serviço de Apoio à Pequenas e Micros Empresas. Comércio e serviços: reciclagem de resíduos. Estudo de mercados: Comércio e serviços: reciclagem de resíduos. Bahia: SEBRAE, 2017.

SILVA, J. O.; SILVA, A. B.; JESUS, T. B.; TOLEDO, O. C.. Heavy metal concentrations in the water of a dam by an open dump in Teofilândia, state of Bahia, Brazil. Revista Brasileira de Geografia Física, v.11, n.6, p.2109-2117, 2018. DOI: http://dx.doi.org/10.26848/rbgf.v11.6.p2109-2117

SIQUEIRA, T. M. O.; ABREU, M. J.. Fechando o ciclo dos resíduos orgânicos: compostagem inserida na vida urbana. Ciência e Cultura, v.68, n.4, p.38-43, 2016. DOI: http://doi.org/10.21800/2317-66602016000400013

URBAN, R. C.. Índice de adequação do gerenciamento de resíduos sólidos urbanos como ferramenta para o planejamento: aplicação no estado de São Paulo. Engenharia Sanitária e Ambiental, Rio de Janeiro, v.21, n.2, p.367-377, 2016. DOI: http://dx.doi.org/10.1590/s1413$\underline{41522016140543}$

A CBPC - Companhia Brasileira de Produção Científica (CNPJ: 11.221.422/0001-03) detém os direitos materiais desta publicação. Os direitos referem-se à publicação do trabalho em qualquer parte do mundo, incluindo os direitos às renovaç̃̃es, expansões e disseminações da contribuição, bem como outros direitos subsidiários. Todos os trabalhos publicados eletronicamente poderão posteriormente ser publicados em coletâneas impressas sob coordenação da Sustenere Publishing, da Companhia Brasileira de Produção Científica e seus parceiros autorizados. Os (as) autores (as)

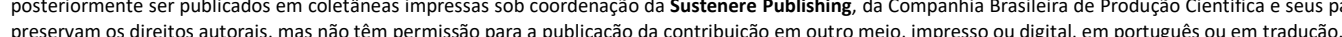

